\title{
A graça da virtude
}

\author{
Leonardo Rennó R. Santos
}

Bolsista Fapesp de doutorado, FFLCH-USP 

A noção de bela aparência estava longe de ser propriamente tematizada quando Kant começou a meditar sobre os tópicos de refinamento e sensibilidade, mais de quatro décadas antes da edição de sua "doutrina do conhecimento do ser humano". E, contudo, parece ser possível o rastreamento nas Observações sobre o sentimento do belo e do sublime (Observações) de um conjunto de argumentos que de fato testemunharão a importância que Kant já ligava ao jogo do ser versus parecer-ser no terreno da moral.

É notório que este texto será o último representante de um projeto kantiano de moral baseado na sensibilidade, no qual os princípios práticos, longe de funcionarem como "regras especulativas", são para o filósofo "a consciência de um sentimento que vive em cada coração humano". Sendo "engendrada por princípios" (Kant, 1993, p. 32) que não devem visar senão a universalidade, a verdadeira virtude se mostra aqui sobredeterminada tanto pelo fundamento de benevolência quanto pelo de respeito. De qualquer modo, antes que defender a partir daí um otimismo moral desmedido, Kant também levará em consideração as fraquezas da natureza humana, presumindo conseguintemente certa ineficácia deste sentimento moral universal numa grande parcela dos homens. Em reposta a esta situação, Kant conjectura que a Providência teria implantado nos homens "instintos de solidariedade" (Ibid., p. 33), quais sejam de compaixão e condescendência, que mesmo não sendo virtudes genuínas, cujos princípios são o fundamento de ações nobres e justas, funcionariam certamente como suplementos a esta, por serem fundamentos de belas ações, sendo então definidas como virtudes de adoção.

Entretanto, em vista do bem público, estes suplementos se revelam inócuos, motivo que leva Kant a supor que a Providência similarmente teria implantado nos homens outro sentimento, agora mais refinado, capaz de "contrabalançar o rude egoísmo e a luxúria vulgar", e mesmo de retirar "a indolente natureza humana” da inação. Desta maneira, o sentimento de honra e, portanto, o de pudor, enquanto fundamento-de-ação que leva essencial- 
mente em conta a opinião alheia, impele os homens a sacrifícios, cuja causa não é senão “a aparência exterior”, uma "quimera, que, apesar de muito artificial em si mesma, é deveras útil, como quando o juízo de outrem determina o valor de nós mesmos e de nossas ações" (Ibid., p. 33).

Em comparação, assim, com o "nobre decoro, que é a beleza da virtude" no indivíduo que "subordina a inclinação particular" ao "sentimento da beleza e da dignidade da natureza humana" (Ibid., p. 32), este decoro efêmero não passará de um cintilamento de virtude, por certo útil na medida em que por meio dele os homens em sociedade de fato temperam a sua rudeza e vulgaridade. Prova disto, o temperamento colérico, que ocupará neste texto a posição de símile da conduta social, precisamente porque seu comportamento, sendo artificial, prevê a adoção de "diversos pontos de vista, a fim de julgar seu decoro segundo a posição diversa do espectador" (Ibid., p. 39). É apenas devido à realidade do sentimento moral universal que, nas Observações, o colérico se desqualifica em face do melancólico, possuidor de "um elevado sentimento da dignidade da natureza humana" (Ibid., p. 37).

No entanto, quando a moral for realocada por Kant para a esfera racional ${ }^{1}$, aquilo que meramente cintilava, ofuscando a realidade do sentimento moral, passará a verdadeiramente brilhar no palco da civilização, viabilizando então o descortino “[d]a inocente ilusão de nós mesmos" (Id., 2006, p. 50)². Com efeito, é a noção de ilusão como própria da razão o termo médio que contrapesará este descompasso entre o nobre e o efêmero decoro, fazendo surgir assim a de bela aparência, a qual por sua vez autorizará a aparência moral [moralischen Schein].

1 Cf. o $\$ 9$ de Kant, 2005.

2 Para toda remissão ao original usou-se Anthropologie in pragmatischer Hinsicht. In: Schriften zur Anthropologie, Geschichtsphilosophie, Politik und Pädagogik 2. Band XII, Frankfurt am Main: Suhrkamp, 1977. 
Em vista da economia argumentativa da Didática Antropológica, primeira parte da Antropologia pragmática dedicada à investigação das faculdades superiores da alma, a noção de bela aparência estará vinculada à de engano [Blendwerk], mais geral e estabelecida como sua condição de possibilidade. Segundo a notação do $\mathbb{1 3}$, o "engano provocado no entendimento pelas representações dos sentidos (praestigiae) pode ser natural ou também artificial, e é ilusão (illusio) ou fraude (fraus)" (Ibid., p. 48).

Nos parágrafos anteriores, ao apresentar uma defesa da sensibilidade, Kant havia mostrado que a matéria disponível para a apresentação dos conceitos do entendimento é sempre aquela oferecida pelas representações sensíveis (Ibid., p. 52) enquanto intuições fictícias e percepções reais. Donde se segue que é de incumbência da faculdade de entendimento se encarregar primordialmente da avaliação sobre a maneira como estas modulações da sensibilidade³ lhe são entregues, sem o que acabará se enganando.

Mas é precisamente isto o que Kant já havia esclarecido na Dialética transcendental da CRP no que tange à geração natural de ilusões que "está inseparavelmente ligada à razão humana" (Id., 1989, B 354). Desta maneira, com a Antropologia pragmática é possível tanto inferir que - no tocante à aparência empírica devedora da transcendental - também existirão formas naturais em face das artificiais de engano, quanto esperar que, após a avaliação sobre as ações peculiares da imaginação (Torres Filho, 1974, p. 94-96), o entendimento se responsabilize por ou dissipar aqueles enganos artificiais ou reabilitar a função legítima, porque essencial, daqueles naturais ${ }^{4}$. Numa palavra, caberá ao entendimento o trabalho de desmontar a estrutura degenerada da fraude

3 Cf. para contraste: Kant, 1989, B 351.

4 "A Ciência, pretensamente juiz do erro-distração, torna-se o melhor exemplo do erro-ilusão. A falsidade não é mais uma falta com relação a uma verdade sempre segura (desde que eu preste atenção), mas um descuido quanto à fragilidade do saber”. LEBRUN, Gérard. Do erro à alienação. In: Lebrun, 1993, p. 22. 
[Betrug], ou de dar oportunidade à aplicação legítima da ilusão [Täuschung/Illusion].

Grosso modo, a dissolução da fraude (Kant, 2006, p. 49) se dará pela confrontação do entendimento entre os fenômenos do sentido interno e a realidade das intuições empíricas, como confirma a seguinte sugestão 'terapêutica' de Kant: “A propensão ao ensimesmamento, junto com as ilusões do sentido interno que dela decorrem, só pode ser corrigida se o ser humano é reconduzido ao mundo exterior e, com isso, à ordem das coisas que se apresentam aos sentidos externos" (Ibid., p. 61).

Por outro lado, a aplicação legítima da ilusão será garantida pela mesma via segundo a qual a fraude pretendia se assegurar, qual seja pela propensão da razão humana para o engano, "que não ofende o uso lógico do entendimento e responde a uma necessidade da Razão” (Prado Jr., 4 p. 54). No $\int 14$ da Didática Antropológica, que visa tratar justamente da aparência moral permitida, Kant se posiciona da seguinte maneira a respeito da sua versão positiva:

A natureza implantou sabiamente no homem a propensão a se deixar de bom grado enganar, quer para salvar a virtude, quer para conduzi-lo a ela. A boa e honrosa decência é uma aparência exterior que infunde respeito aos outros (não se fazer vulgar) (Kant, 2006, p. 51).

Sobre o papel que a sábia natureza executa aqui, não deve igualmente ser desvalorizado o seu vínculo estreito com outro posicionamento da CRP apresentado no Apêndice à dialética transcendental. Lá Kant defende a natureza compreendida teleologicamente como uma noção profícua para os agrupamentos das coisas do mundo, isto é, de seus fenômenos (Id., 1989, B 724), com o objetivo de que a razão alcance a sua "maior unidade sistemática” (Ibid., B 722), e não, ao contrário, uma abertura para a investigação, ou defesa, dos desígnios de um demiurgo. Com a Antropologia Pragmática, elucidar-se-á o desvario ou sonho de 
visionário de tal conduta, ambas desvirtuações das faculdades superiores da alma escoradas no emprego equivocado da imaginação: "Foi assim com as exaltadas e excitantes sensações internas de uma Bourignon, ou as exaltadas e assustadoras de um Pascal" (Id., 2006, p. 61)5.

Mas porque natural, o engano precisará claramente servir para algum fim, como afirma a terceira proposição da Ideia de uma história universal de um ponto de vista cosmopolita (História cosmopolita): "A natureza não faz verdadeiramente nada supérfluo e não é perdulária no uso dos meios para atingir seus fins" (Id., 2003, p. 6). A inflexão antropológica então será taxativa: a utilidade desta disposição para o engano - no plano pragmático traçado por Kant - será a de infundir respeito aos homens por suas aparências exteriores decorosas. Que seja lembrado, de qualquer modo, que já na História cosmopolita, Kant desautorizava qualquer engano quanto ao pouco caso revelado pelos homens a respeito do seu destino descoberto pela razão, por comparação ao desatino dos seus desejos e impulsos egoístas (Kant, 2003, p. 4). No entanto, serão os produtos desta intratabilidade, enquanto fenômenos sociais que compõem o mundo da cultura, aqueles a serem agrupados segundo uma perspectiva teleológica engendrada pela razão para a condução de seus negócios.

E é precisamente este o cerne da questão. A razão nos homens, entendida na História cosmopolita como "faculdade de ampliar as regras e os propósitos do uso de todas as suas forças muito além do instinto natural" (Ibid., p. 5) terá por efeito tanto o afastamento daquilo que neles é meramente instinto, quanto a sua reiteração incessante. Donde a compreensão de que esta ambivalência está inscrita na natureza humana; tanto de tentar

5 Vale notar que já nas Observações, Kant excluía de sua investigação "a inclinação que se liga a visões elevadas do entendimento" [p. 21], tais como a de Kepler. Crítica que apenas se acentuará com o opúsculo pré-crítico Sonhos de um visionário explicados por sonhos da metafísica de 1766, cujo alvo imediato era o místico Swedenborg. 
refazer o estado de tutelado, ou por preguiça ou covardia, segundo a inscrição do renomado opúsculo sobre o Esclarecimento (Kant, 2005, p. 64), ou pela inclinação à comodidade (Id., 2006, p. 50) como afirmará a Antropologia pragmática, quanto de vislumbrar seu termo colocando-se em comunidade com outros homens. É este o antagonismo fundamental que Kant julga ser "evidente na natureza humana" (Id., 2003, p. 8).

Com efeito, os fenômenos sociais provenientes desta tensão, segundo o $\int 14$ da Antropologia pragmática, ocorrerão porque, não se deixando passar por vulgar, um homem forçará seu companheiro a também executar o mesmo papel social, a fim de que este possa de igual maneira ser portador de equivalente respeito. Engendrar-se-á disto regras de comportamento que, no fim, não constituirão senão a bela aparência, ou seja, a "distância necessária para não rebaixar um a mero instrumento do gozo do outro" (Id., 2005, p. 51). É por isto que à luz da discussão sobre o engano, o que à primeira vista poderia passar por um logro, isto é, fraude, não chegará a tanto, já que todos os homens consentem em não ser exatamente sinceros em sociedade:

Feitas as contas, quanto mais os seres humanos se tornam civilizados, tanto maior é o número de atores; eles aparentam simpatia, respeito pelos outros, recato, altruísmo, sem enganar ninguém com isso, porque cada um dos demais está de acordo que não se está sendo exatamente sincero, e também é muito bom que as coisas sejam assim no mundo (Id., 2006, p. 50).

Mediante esta avaliação, o acordo mútuo de insinceridade entre os homens garantirá que tal pacto não seja julgado como desonesto, o que acarretaria ver na disposição natural para o engano um mal, essencial e intransponível, da razão. Contrariamente, ao executar tais papéis, os homens terminam por desenvolver o intricado sistema de regras e condutas sociais, viabilizando assim o belo intercurso entre criaturas que, não suportando viver juntas, não podem em todo caso prescindir de sua vizinhança. 
A partir disto, então, a civilização não passará de início de produção de atores que vendem para vantagem própria as suas personagens sob a forma de virtudes verdadeiras, conquanto não passando de "sinais vazios" (Ibid., p. 51 (modificado)). Ora, como já defendia a Histórica cosmopolita, tal situação é tudo de que necessita a Natureza para a realização de seus objetivos a respeito dos homens: preencher, com economia de princípios, tais vacuidades com motivos genuínos para a efetivação da destinação moral humana:

Pois, porque os homens representam esse papel, as virtudes, cuja aparência apenas afeta por um longo espaço de tempo, são por fim pouco a pouco realmente despertadas e passam a fazer parte do caráter. - Fraudar [betrügen], porém, o fraudador [Betrüger] que há em nós mesmos, a inclinação, é, por sua vez, voltar a obedecer à lei da virtude, não fraude [Betrug], mas inocente ilusão de nós mesmos (Ibid., p. 50 (modificado)).

O conceito de virtude, definido na Antropologia pragmática como força moral do agente no cumprimento do dever (Ibid., p. 46), não deve provir do hábito, coleção de ações mecanicamente reiteradas que engessa a liberdade do espírito; pelo contrário, a virtude deve constrangê-lo por se apresentar como exercício original e constante da atividade racional. É, portanto, o antípoda da comodidade, inclinação engendradora do hábito, que, todavia, precisa travesti-la a fim de que, julgando se dedicar aos próprios assuntos, os homens inadvertidamente passem a acreditar na realidade daqueles sinais vazios e, assim, ponham-se a se esforçar deliberadamente no cumprimento do dever. O que de início não passava de inocente ilusão, transforma-se em disposição para a ação, com a qual a parcimoniosa Natureza consegue efetivar aqueles papéis sociais.

É, portanto, na passagem da correção da fraude para a aplicação autêntica da ilusão no plano das faculdades da alma que, no tocante ao intercurso humano, o processo civilizatório deixa-se 
entrever não tanto como oficina de atores, definido assim como uma espécie de cláusula de garantia, quanto como formação de cidadãos do mundo, isto é, de implantação nos homens do gosto pela própria instrução. Passagem de fato árdua, tal como é observado no $\$ 67$, onde Kant mostra que "toda exposição da própria pessoa ou da sua arte feita com gosto pressupõe um estado de sociabilidade (para se comunicar), que nem sempre é sociável (de participação no prazer dos demais), mas de início é geralmente bárbaro, insociável e de mera rivalidade" (Ibid., p. 138).

A sociabilidade, então, é definida aqui apenas como a capacidade dos homens para entrarem em acordo acerca de seus pensamentos e impressões por meio da comunicação, embora sobre este ponto nenhuma informação possa ser analiticamente extraída sobre o grau volitivo do seu exercício. Com efeito, à luz dos opúsculos sobre a História, a aurora da convivência humana se supunha insociável por estar apoiada nos primeiros ensaios de uma razão embrutecida. Apresentar-se com gosto naquele momento indicava antes subterfúgios para obtenção de vantagens que garantissem a sobrevivência de criaturas rudes num mundo ainda muito obscuro. No opúsculo Começo conjetural da história humana (Começo conjectural), Kant pondera da seguinte maneira sobre o abandono do estado de mera natureza pelo homem:

[...] sem dúvida uma mudança honrosa, mas, ao mesmo tempo, muito perigosa, porque o retira da inocência e da segurança próprias ao estado infantil, como de um jardim no qual encontrava sustento sem trabalho (Gênesis, 3:23), e o lança no mundo, onde o aguardam tantos riscos, penas e males desconhecidos (Ibid., p. 23).

Todavia, não obstante tratar-se no início de estratégias de sobrevivência mais do que de fruição no objeto, ou até mesmo, como possivelmente devia ter se configurado, de ambas estas perspectivas estarem imiscuídas nas suas representações obscuras, as primeiras exposições de si mesmos e dos frutos de sua técnica 
com gosto já assinalavam nos homens uma operação peculiar da razão de, "com a ajuda da imaginação, provocar de modo artificial novos desejos que, além de não se fundarem numa necessidade natural, estão com ela em contraste direto" (Ibid., p. 17). Aos homens, portanto, foi facultada a possibilidade de gerência do sentimento de prazer e desprazer sensível, provocando-o ou suprimindo-o segundo seus objetivos paulatinamente descobertos e de acordo com o grau de habilidade de seu controle lentamente adquirido.

Desta forma, e em vista das faculdades do ânimo, a consciência do específico sentimento de prazer causado pelo jogo de representações emergirá com a aparagem das arestas excessivamente insociáveis destas criaturas ainda rudes. Isto equivale à defesa de que extrair prazer consciente do gosto, condição necessária para que o estado de sociabilidade se torne sociável, ou seja, "de participação no prazer dos demais", é de fato uma conquista humana do controle sobre o sentimento de prazer e desprazer enquanto faculdade superior da alma. Nesta medida, a apresentação aprazível de que tratava o $\$ 67$ terá como resultado o abrandamento da intratabilidade humana, o que por sua vez vai permitir, pelo gerenciamento mais adequado do prazer, o estabelecimento do estado de complacência (Id., 2005, p. 50); ou ainda, de "um espaço de jogo onde, de comum acordo, os parceiros renunciam a prejudicar-se e a atacar-se, tanto no comércio ordinário quanto no que se refere ao amor" (Starobinski, 1989, p. 61).

Já foi mostrado que os fenômenos sociais engendrados por este estado de coisas pertencem à bela aparência. Kant, porém, não empregará este delicado e intrincado sistema de condutas como prova categórica de uma vivência moral já plenamente conquistada. Pelo contrário, funcionando como "condição negativa do gosto" (Kant, 2006, p. 142), esta noção é apresentada como contraprova da capacidade humana de aprimoramento moral, já que são estas as condutas que, animando os homens para a comunicação, arrefecem a sua tendência para a utilização de seus 
companheiros como simples objetos de gozo, efeitos portanto prenunciadores do estado de moralidade. É neste sentido que, de acordo com Kant, "o gosto ideal tem uma tendência a incentivar externamente a moralidade” (Ibid., p. 141). Assim, mesmo sem o dizer, o filósofo parece autorizar na Antropologia pragmática a seguinte fórmula acerca do juízo de gosto: gosto é o princípio vivificador dos costumes por meio da bela aparência, tanto porque é ela aquilo que retira os homens da atonia artificial engendrada pelo hábito, marca dos costumes, quanto porque é o juízo de gosto o elemento instigador nos homens para a formação como cidadãos do mundo.

Por conseguinte, é este tipo de juízo aquele que conduzirá as criaturas intratáveis visadas nos escritos sobre história a se porem à mesa, fato que leva a Tischgesellschaft [sociedade de comensais] a poder ser representada como "a imagem particular da universalidade” (Foucault, 2008, p. 64). Neste sentido, Kant observará no fechamento da Didática Antropológica que "o bem-estar que parece melhor se afinar com tal incremento [da verdadeira humanidade por meio da conversação] é uma boa refeição em boa companhia (e, se possível, também variada)" (Kant, 2006, p. 175). Segundo esta apreciação, as sociedades de comensais são a manifestação humana que exprime melhor a sociável sociabilidade, evidência assim do polimento da intratabilidade humana, o que faz com que o guia do intercurso entre os homens seja agora o prazer da comunicação de seus pensamentos e sentimentos.

A rigor, o acento desta disposição humana recairá sobre a pressuposição de um exercício contínuo e afinado da arte da conversação por intermédio da qual os cidadãos cosmopolitas se aprimoram moralmente, já que tal arte é capaz de promover a um só tempo a lapidação da sensibilidade (enquanto sentido e imaginação) e o refinamento do entendimento. Assim, se o que importa para o dito Banquete kantiano é o cultivo das faculdades apenas obtido pelo colóquio, parece ter sido Hume a inspiração desta proposição. Diz o escocês: 
[...] em comparação com os aperfeiçoamentos que [os homens] recebem do conhecimento e das artes liberais, é para eles impossível não sentirem um acréscimo de humanidade [humanity], a partir do próprio hábito de conversarem juntos, e de contribuírem mutuamente para o prazer e o entretenimento (Hume, 1994, p. 107).

É sabido que esta formulação da questão, disposta por Hume no artigo Do refinamento nas artes, visava responder à Querela sobre o Luxo, instigada no início do século XVIII por Voltaire com o poema Le Mondain (Voltaire, 1961, p. 203). Já para o caso de Kant, tratava-se antes de tirar proveito deste deslocamento temático em resposta à querela, com o objetivo de, uma vez estabelecido o âmbito prático e, por extensão, o conceito de natureza humana, conduzir a questão sobre o aprimoramento das faculdades humanas deste "ponto de vista sócio-econômico" (Monzani, 1995, p. 41) para o pragmático, criticamente justificado.

Por isto, se para Kant a comensalidade se revela exemplar na realização factual da ideia de Humanidade [Humanität] enquanto "modo de pensar que unifica o bem-estar com a virtude nos relacionamentos" (Kant, 2006, p. 174), ela chega a tanto porque consegue de fato obstar, mesmo reparar, as deformações da virtude que, aos olhos de Kant, não passavam de ardis do amor próprio (Ibid., p. 52): "O purismo do cínico e a mortificação da carne do anacoreta, sem bem-estar social, são formas desfiguradas da virtude e não convidam para esta: ao contrário, abandonadas pelas Graças, não podem aspirar à humanidade" (Ibid., p. 178).

Com efeito, esta disposição para se colocar à mesa como contraponto da intratabilidade humana apenas afiança o regramento decoroso de uma linguagem em comum (Foucault, 2008, p. 64), versão comensal do pluralismo (Ibid., p. 30) mediante o qual o solipsismo afeito ao estado de menoridade, sendo combatido pela Graça da Virtude, outro título então para a bela aparência, dá azo à frutificação da vocação moral dos homens. Isto que, ao menos 
in nuce, já rondava o pensamento de Kant em seus primórdios, tal como desponta da sentença final das Observações:

Mas, sobretudo, é de se desejar que o segredo ainda não revelado da educação seja arrancado da antiga ilusão, para que o sentimento moral cedo se eleve a um sentimento ativo no seio de todo jovem cidadão do mundo, a fim de que nem todo refinamento se esgote no divertimento fugaz e ocioso de julgar com mais ou menos gosto o que ocorre fora de nós (Kant, 1993, p. 79 (itálico nosso)).

\section{Bibliografia}

FOUCAULT, Michel. Introduction à l'Anthropologie. In: KANT, I. Anthropologie du point de vue pragmatique. FOUCAULT, M. (trad.), Paris, Vrin, 2008.

HUME, David. Of refinement in the arts. In: Political Essays. HAAKONSSEN, K. (Ed.), Cambridge, Cambridge University Press, 1994 .

KANT, Imannuel. Anthropologie in pragmatischer Hinsicht. In:

Schriften zur Anthropologie, Geschichtsphilosophie, Politik und Pädagogik 2. Band XII, Frankfurt am Main, Suhrkamp, 1977.

. Antropologia de um ponto de vista pragmático. MARTINS, C. A. (trad.), São Paulo, Iluminuras, 2006.

. Começo conjectural da história humana. MENEZES, E. (trad.), São Paulo: Editora Unesp, 2009.

Crítica da faculdade de julgar. ROHDEN, V.; MARQUES,

A. (trad.), $2^{\mathrm{a}}$ ed., Rio de Janeiro, Forense Universitária, 2005. Crítica da razão pura. MORUJÃO, A. F.; SANTOS, M. P. (trad.). $2^{\mathrm{a}}$ ed., Lisboa, Fundação Calouste Gulbenkian, 1989.

. Forma e princípios do mundo sensível e do mundo inteligível. SANTOS, P. L. (trad.). In: . Escritos pré-críticos. São Paulo,

Editora Unesp, 2005.

Ideia de uma história universal de um ponto de vista cosmopolita. TERRA, R. R. (trad.), São Paulo, Martins Fontes, 2003. 
KANT, Imannuel. Observações sobre o sentimento do belo e do sublime. FIGUEIREDO, V. (trad.), Campinas, Papirus, 1993.

Resposta à pergunta: Que é "Esclarecimento"?. In: . Textos Seletos. Petrópolis, Vozes, 2005.

LEBRUN, Gérard. Do erro à alienação. In: Sobre Kant. TORRES FILHO, R. R. (org.), São Paulo, Iluminuras, 1993.

MONZANI, Luiz R. Desejo e prazer na idade moderna, Campinas: Editora da Unicamp, 1995.

PRADO Jr., Bento. Erro, Ilusão, Loucura. São Paulo: Ed. 34, 2004.

STAROBINSKI, Jean. Le remède dans le mal: critique et légitimation de l'artificie à l'âge des Lumières. Saint-Amand, Gallimard, 1989.

TORRES FILHO, Rubens R. O Espírito e a Letra: A Crítica da Imaginação Pura, em Fichte. São Paulo, Ática, 1975.

VOLTAIRE. Le Mondain. In: . Mélanges. Bibliothèque de la Pléiade, Paris, Gallimard, 1961. 
